\title{
Family psychoeducation for people living with schizophrenia and their families
}

\author{
Carol Harvey
}

\begin{abstract}
SUMMARY
Most people with schizophrenia have frequent contact with their families. Therefore, the family should be involved in their relative's treatment and care wherever possible, so that they can contribute to that person's recovery and the family's own needs for information, support and treatment can be addressed. Family psychoeducation refers to a group of structured psychotherapeutic interventions that involve the person with schizophrenia and their family as partners in care. Trained practitioners adopt a collaborative approach to information sharing and provide training in coping, communication and problem-solving skills. This article describes the common principles and techniques of family psychoeducation (FPE), along with the substantial evidence for its benefits for families, especially reduced relapse rates for the person with schizophrenia. Despite recommendations in clinical practice guidelines, FPE is not widely available throughout the world. The current challenge is to address this through systemic approaches to practice change and tiered approaches to family service delivery.
\end{abstract}

\section{LEARNING OBJECTIVES}

- Appreciate the needs of families and recognise how these may be addressed by family psychoeducation

- Understand the evidence for family psychoeducation

- Delineate the key elements of family psychoeducation and consider how it may be applied in practice

\section{DECLARATION OF INTEREST}

None.

The treatment of schizophrenia has involved psychotherapeutic work with families since the 1950s. Different models have developed, informed by psychoanalysis, systems theory, behavioural and cognitive-behavioural psychology, educational approaches and the family advocacy movement (Farhall 2012; Killackey 2015).
Family psychoeducation (FPE) describes a number of closely overlapping interventions provided to people with schizophrenia and their families. These structured psychotherapeutic interventions were originally developed with the primary aim of decreasing the number of relapses of illness. A strong evidence base has been generated for these various forms of FPE in supporting people with schizophrenia to achieve this outcome. It has also become apparent that FPE offers other benefits to all family members, such as improved relationships within and outside the family.

\section{Terminology}

I will use the term family to include a person's immediate family members (including dependent children) and partner, as well as members of their wider social support network, which may include other relatives and friends. This acknowledges that individuals with schizophrenia may have diverse people of significance to their health and wellbeing in their immediate circle - often, but not exclusively, family members.

Family psychoeducation is my preferred term to describe this group of structured psychotherapeutic approaches. They are also sometimes referred to in the literature as family interventions, although this term is increasingly used more broadly to encompass all available forms of intervention with families (Fadden 1998; Lucksted 2012). The term 'family psychoeducation' in itself can be misleading, since it implies a strong focus on psychoeducation. Although psychoeducation is a key element, FPE includes many other therapeutic elements and aims to enhance family skills and knowledge, typically within a consultative and collaborative approach to the work (Dixon 2001).

Family psychoeducation differs from traditional or predominantly systemic family therapy approaches, such as structural family therapy. These assume that dysfunctional family communication and interactions cause schizophrenia and that addressing these leads to treatment or cure (Fadden 1998; McFarlane 2003). Thus, family therapy approaches
Carol Harvey is a Professor in the Department of Psychiatry, University of Melbourne, a consultant psychiatrist in the North West Area Mental Health Service and Director of the Psychosocial Research Centre in Melbourne, Australia. Her clinical work, service development and research focus on psychosocial approaches to prevention, treatment and recovery from mental illness. She has research expertise in epidemiology and service models. Carol is a committed teacher, trainer and supervisor of rehabilitation and recovery approaches in mental health and content lead for the Australian online curriculum, Mental Health Professional On-line Development (MHPOD).

Correspondence Professor Carol Harvey, Psychosocial Research Centre, Department of Psychiatry, University of Melbourne and North Western Mental Health, 130 Bell

Street, Coburg, Victoria 3058, Australia.

Email: c.harvey@unimelb.edu.au

\section{Copyright and usage}

(C) The Royal College of Psychiatrists 2018 
aim to work with the whole family to change their response to the mental disorder and to each other. They do this by exploring beliefs, patterns of interaction and behaviour within the family to avoid unhelpful (vicious) cycles of interaction and to promote helpful (virtuous) cycles (Burbach 1996; Farhall 2012). In contrast, FPE - which is the subject of this article - involves a collaborative approach to information sharing and provides training in coping, communication and problem-solving skills so that the family may better support their relative's recovery (McFarlane 2003; Lucksted 2012).

\section{People with schizophrenia and their relationships with family}

It is sometimes falsely assumed that few people with schizophrenia in industrialised societies have ongoing family relationships. This is because a minority of these individuals are married and the dominant cultural emphasis is on adults, whether married or unmarried, leaving their family of origin to become more 'independent'. However, a large majority of people with schizophrenia live with and/or maintain close contact with family and other support people (Onwumere 2010). For example, the 2010 Australian survey of people with psychosis showed that frequent face-to-face contact with family members in the previous year was the norm: $56.5 \%$ had almost daily contact and another $17.1 \%$ had at least weekly contact (Morgan 2012). This underscores the importance of involving families in treatment for a number of reasons (Wallcraft 2011; Harvey 2013). Most family members want to be involved in the treatment and care of a relative with severe mental illness and to assist with their recovery (Parker 2010) and most people with schizophrenia and other severe mental illnesses are supportive of such involvement (Murray-Swank 2007). Families often have a great deal of knowledge and experience of their relative's illness and the nature of their relapses, likely stressors and coping capacity. Further, they are usually well placed to support their relative to act early to prevent a relapse. Family involvement then is likely to enhance the capacity of practitioners and services to effectively support the person with schizophrenia (Wallcraft 2011).

\section{Family needs}

Although most families want to be constructively involved in their relative's treatment, often they do not have the necessary knowledge or skills to undertake this role. Many also experience the continuing impacts of their relative's mental illness and therefore need treatment and support in their own right (Harvey 2013). Families of people with psychotic illnesses experience higher rates of depression and anxiety, greater social isolation and decreased quality of life compared with the rest of the community (Hayes 2015). For example, a study in Australia found that carers were nearly ten times more likely to be socially isolated than a matched community group, and over $40 \%$ met criteria for probable anxiety or depression (Hayes 2015).

Unfortunately, family carers often report a lack of engagement by mental health practitioners, as well as inadequate provision of information and support, which leads to distress and frustration (Dixon 2001; Wynaden 2005; Harvey 2013). Family psychoeducation (and other family interventions, education and support) offers the prospect of addressing the needs of all family members (Harvey 2013).

\section{Ways to address family needs}

In addition to the various forms of traditional family therapy, several models of family intervention have developed to address family needs: some are delivered by practitioners, some by family peers and, increasingly, practice has evolved so that specific family interventions may be delivered by either or both of these groups together (Dixon 2001; Killackey 2015). As distinct from practitioners, family peers provide support to other family members through their shared understanding and experience. They are not trained as mental health professionals; rather, they are people with lived experience as family members or carers of individuals with a mental illness.

Models of family intervention typically provided by mental health practitioners include individual family consultation, FPE and a range of brief family education programmes. Family interventions that take a peer-to-peer approach include family education groups, family support groups and individual counselling, support and advocacy provided by trained carers. In my own mental health service in Melbourne, family peers have been employed and trained to provide individual family consultation using a specific model (single-session family consultation) as well as a form of FPE (behavioural family therapy) (Falloon 2004; Farhall 2012). This illustrates the evolution of practice regarding who may be trained to offer family interventions (O‘Hanlon 2015; Visa 2015).

In this article I focus on FPE since it is very well researched and has a strong evidence base for efficacy in delivering improved outcomes for people with schizophrenia and, increasingly, for their families.

\section{Development of FPE and the role of expressed emotion}

The development of FPE was informed by a growing recognition of the importance of involving families in 
treatment (McFarlane 2003). It was underpinned by the stress-vulnerability model of schizophrenia (Zubin 1977), in which a relapse is understood as arising from the interaction between a person's vulnerability, their coping ability and the stressors to which they are exposed.

Early FPE approaches arose from research demonstrating a link between the emotional climate within the family and the individual's likelihood of relapse. This research found that there was a greater chance of relapse in families who showed a high level of critical, hostile or overinvolved responses (high expressed emotion, high EE) towards the individual than in families who showed low EE (Brown 1972; Vaughn 1976). Thus, FPE aimed to decrease relapse rates by reducing stress arising from critical and hostile responses and overinvolved behaviour (high EE) through the provision of education and skills training (Fadden 1998).

Family responses associated with high $\mathrm{EE}$ are best viewed as an understandable and common reaction to the experience of living with someone with a severe and relapsing condition. Indeed, it has been shown that high EE may be evident in families living with people with other conditions, such as bipolar disorder (Kim 2004). It can also be a feature of staff working with people with severe mental illnesses (Tattan 2000). Despite these observations, an unintended consequence of the original expressed emotion research was that it has sometimes been used as a way of labelling and blaming families for their behaviour (in this case, having high EE). This has led to criticism of the use of this term by family advocates and others (e.g. Hatfield 1987).

\section{Using EE status to identify families who might benefit from FPE}

The expressed emotion paradigm provided a useful impetus for the development of the various FPE models. It also provides a guide to which families might benefit from FPE. However, this is not definitive, since there is evidence for successful outcomes from studies with families of mixed EE status (high and low) as well as unspecified EE status, presumably also mixed (e.g. Barrowclough 1999; Gleeson 2010; Hayes 2014). Further, according to some US studies, the links between carer EE and poor outcomes for their relative with schizophrenia may not be uniform across all cultural groups (Onwumere 2010). These more nuanced findings with regard to $\mathrm{EE}$ status and relapse risk are reflected in recent clinical practice guidelines. Thus, closeness of contact between the family and the person with schizophrenia and whether the person has recently relapsed or is at risk of doing so are emphasised as criteria for offering FPE, rather than family EE status (e.g. NICE 2014). Finally, it is also important not to overlook the needs of low EE families. Although they may not need or want lengthy interventions such as offered through FPE, brief educational interventions with a focus on information sharing and practical resources and supports may be useful for them.

\section{Principles of FPE}

Some of the common principles that underpin all models of FPE, which were agreed by key leaders in these approaches and reported by Dixon et al (2001), are listed in Box 1. Some of these principles are emphasised and elaborated below.

\section{Families as partners in treatment}

Practitioners of FPE adopt a positive and nonblaming attitude towards families (Onwumere 2010). Thus, families are regarded as having made their best efforts to support their relative, as articulated in the manual for practitioners of one FPE model, behavioural family therapy (Falloon 2004). Practitioners are advised to distinguish between the actions of the family and their intentions (Fadden 2006a). Often, families intend to be helpful to a relative with mental illness, but the actual action ends up being unhelpful. By thinking clearly about intention versus outcome, the practitioner can help the family to make new choices about the means they use to achieve their desired ends, by incorporating new coping methods and through problem-solving (Fadden 2006a; Hayes 2014). This practitioner stance is also consistent with a strengths-based approach; that is, assessing the strengths as well as the limitations of the family's ability to support their relative.

The practitioner also aims to involve families as partners in care, consistent with wider developments in mental health practice (e.g. Froggatt 2007; Wallcraft 2011). A specific example of such developments is the concept of the 'triangle of care' (Carers Trust 2013). This argues that the carer, patient and clinician should all be involved in understanding and managing the mental illness, as part of better collaboration and partnership (Carers Trust 2013). Thus, a coaching or partnership relationship is established between mental health practitioners and families, rather than an 'expert and recipient of care' relationship (Killackey 2015). The establishment of this collaborative and supportive relationship enables the expertise and skill of all family members, including the person with schizophrenia, to be acknowledged and harnessed in dealing with everyday problems. 
BOX 1 Common principles for working with families of individuals who have schizophrenia

- Coordinate all elements of treatment and rehabilitation to ensure that everyone is working towards the same goals in a collaborative, supportive relationship

- Pay attention to both the social and clinical needs of the person with schizophrenia

- Provide optimum medication management

- Listen to families' concerns and involve them as equal partners in the planning and delivery of treatment

- Explore family members' expectations of the treatment programme and expectations for their relative

- Assess the strengths and limitations of the family's ability to support their relative

- Help resolve family conflict by responding sensitively to emotional distress

- Address feelings of loss

- Provide relevant information for all family members at appropriate times

- Provide an explicit crisis plan and professional response

- Help improve communication among family members

- Provide training for the family in structured problem-solving techniques

- Encourage family members to expand their social support networks, for example, to participate in family support groups and organisations such as Rethink Mental IIIness and the Carers Trust (UK), SANE and Mental Health Carers and ARAFMI (Australia) and the National Alliance on Mental IIIness (USA)

- Be flexible in meeting the family's needs

- Provide the family with easy access to another professional for ongoing work when the family's psychoeducation ceases

(Adapted from Dixon 2001)

\section{Addressing social and clinical needs of the person with schizophrenia}

A key aspect of FPE is that the approach attends to both clinical and social needs of the person with schizophrenia. Thus, clinical needs may be addressed by collaborative development of explicit crisis plans which incorporate responses to the crisis by professionals as well as significant others, such as family members. Social needs may be addressed through goal setting, which helps the person to resume leisure interests, or pursue study or employment; such needs may also be addressed indirectly through better illness self-management and improved family support as a result of enhanced communication skills (Killackey 2015). Along with this, FPE models assume a biopsychosocial framework for assessment and treatment of schizophrenia. So, in addition to adopting and adapting psychosocial interventions used in individual treatment and rehabilitation, these approaches place emphasis on providing optimal psychotropic medication (Harvey 2013).

\section{Structured yet flexible approach to families}

Family psychoeducation models are typically structured and are described in various books and treatment manuals. Nevertheless, there is scope for flexibility in meeting family needs, as recommended in the common principles (Box 1). Thus, there may be cultural adaptations as well as adjustments to better accommodate the individual's phase of illness (e.g. first episode or later episodes of relapse). It is likely that the practitioner will also need to be flexible and sensitive in helping the family to address their feelings, including grief and loss, guilt and blame, sadness, shame, confusion and powerlessness, as they arise and are expressed (Farhall 2012).

\section{Family psychoeducation models}

Family psychoeducation approaches focus primarily on outcomes for the person with schizophrenia, although the well-being of the family is thought to be an essential intermediate outcome (Dixon 2001). There are three major types of FPE: brief FPE; single-family format; and multiple family groups (Hayes 2013). Recognised FPE approaches include behavioural family therapy (Falloon 2004) and family work (Kuipers 2002), both of which are single-family models, and multiple family groups involving five to seven families (McFarlane 2003).

Family psychoeducation models were typically developed for people with specific diagnoses such as schizophrenia, but later evidence has demonstrated their wider applicability. Although the evidence for benefit is most extensive for individuals with schizophrenia, controlled studies show positive effects for other disorders, especially bipolar disorder and major depression, as well as for schizophrenia co-occurring with substance use (Dixon 2001; McFarlane 2003; Lucksted 2012). There is some evidence for benefit in other psychiatric conditions, such as anorexia nervosa (Dixon 2001; Lucksted 2012).

\section{Shared and active 'ingredients' of FPE}

Although the existing models of FPE appear to differ from one another, a strong consensus about the critical 'ingredients' has emerged under the encouragement of the leaders of the World Fellowship for Schizophrenia (Dixon 2001; McFarlane 2003; Froggatt 2007; Hayes 2013). These are summarised in Box 2. 
BOX 2 Shared and active 'ingredients' of family psychoeducation (FPE) models

- Participants: include the person with schizophrenia in most or all family sessions

- Format: involve single or multiple families

- Number and frequency of sessions: at least 12 , typically fortnightly

- Duration: 9 months to 5 years

- Location: clinic, family home or other community setting

- Techniques: include didactic, cognitive-behavioural, and systemic

- Adaptations: respond to the family's cultural backgrounds and to the phase of the person's illness (e.g. first episode or later relapse)

- Content of sessions:

- information sharing about the disorder, early warning signs and relapse prevention

o skills training (coping, communication, problem solving/goal setting)

(Dixon 2001; Hayes 2013)

\section{Content of sessions: techniques in practice}

In the brief description below of how FPE work is approached, I focus especially on those elements that appear to be essential for effectiveness. My description explicitly refers to one of the singlefamily approaches of Falloon and colleagues, behavioural family therapy (Falloon 2004). This model has subsequently been described by other authors (e.g. Hayes 2014; O’Hanlon 2015) as part of programmes to implement this form of FPE. Best practice suggests that practitioners undertake brief training (4-5 days) that emphasises learning the skills of the model. These are taught through role-play in pairs and small groups, observation of recorded material, and through large and small group discussions. There is a heavy emphasis on practitioners practising the skills involved and receiving facilitated feedback from their fellow participants and the trainers. Some of these techniques may already be familiar to practitioners from other training they have undertaken, but they can be built upon in their subsequent training and work with families. The possible application of such an approach to future developments in this area will be discussed later.

\section{Assessment}

An assessment of the family, both as individuals and as a family, is made during the first few sessions.

\section{Individual assessment}

The practitioner conducts individual interviews with family members, including the person with schizophrenia. Each individual is asked about their background, their understanding of their relative's (or their own) mental illness, the impact of the mental illness on themselves and their day-to-day life, and their personal goals. This process is helpful in developing a picture of the family's strengths and needs, as well as building a rapport between the practitioner and family members. Family members feel they are being listened to (often for the first time) and their experiences are being valued in their own right, and not simply because of what they might be able to reveal about their relative's illness. Each individual is also asked to set some concrete personal goals to be achieved by the completion of the family work. Examples might concern exercise (such as walking twice a week or attending a weekly gym session), leisure (such as going out for a meal or to watch a film) or socialising (such as meeting a friend).

\section{Family assessment}

Meeting as a group with the practitioner, the family are asked about how they solve problems and achieve goals together. Detail is elicited about family discussions, who gets involved, how progress is assessed, the family's problem-solving skills and their attitudes to consensus or compromise. Following this, the family are asked to select a real and shared problem or concern and to work through this, thereby showing the practitioner how they solve a problem. The practitioner observes the family's strengths and assesses areas where additional skills could be usefully learnt. These observations are summarised and fed back to the family and linked to future skills training sessions and how these might help.

\section{Information sharing about the illness, early warning signs and relapse prevention}

The purpose of information sharing is to recognise and share the knowledge and expertise of all parties (the person with schizophrenia, the family and the practitioner). It enables all parties, including the practitioner, to gain a better understanding of the needs and experiences of all family members.

Often, the family's previous discussion of mental illness will have been quite minimal. This might have been for a variety of reasons. For example, they might have been worried that discussion would reinforce unusual ideas or behaviours in their relative. A frequent concern for all parties is that information sharing might upset other family members or make things worse.

The information sharing is tailored to the family's needs. In line with the aforementioned coaching or partnership relationship, the person with 
schizophrenia is encouraged to become the 'expert' and explain their symptoms to their family. This can be a very powerful experience for families as they hear, often for the first time, what it is like to live with 'voices' or delusions and other symptoms of schizophrenia.

The family also discuss and agree on a list of early warning signs and are encouraged to record this on paper. This relapse prevention plan will include a list of agreed actions and people to contact should there be signs of an impending relapse.

\section{Communication skills}

The types of communication skill that are taught, and their benefits are described in Box 3 (Falloon 2004). These skills are acquired through a sequence of steps outlined in Box 4. The practitioner should model these skills, wherever possible, in sessions. All these skills are alternatives to high-EE or less helpful interactions such as hostility, criticism and emotional overinvolvement. Without necessarily stating that families are doing something 'wrong', the training in communication skills provides alternatives for effectively communicating concerns and articulating difficult feelings without blame, resentment or aggression. Such conversations may have

\section{BOX 3 Communication skills and their benefits}

\section{Expressing pleasant feelings}

This is direct verbal communication that informs a person that the speaker is pleased with something that the person has done - it helps the family to focus on positive things and notice helpful things that each of them does

\section{Making a positive request}

This involves using assertive language to make a constructive request for behaviour change - it helps the family to increase their efficiency at resolving problems and achieving goals

\section{Active listening}

This is the skill of consciously listening to someone, discussing their concerns and clarifying problem areas and ideas - it provides an opportunity for the speaker to clarify their thoughts and feelings and for the listener to better understand the speaker's problems and concerns, and it helps the family to solve problems and achieve goals

\section{Expressing unpleasant (or difficult) feelings}

This involves talking about negative feelings such as unhappiness, frustration, anxiety or anger, without blaming, and is combined with doing something to try to resolve the problem, for example making a positive request - it helps the family resolve problems and also increases intimacy

(Falloon 2004; Fadden, 2006a)

\section{BOX 4 Steps in communication skills training}

Step 1: The practitioner encourages the family to identify and discuss the benefits of a particular skill

Step 2: The practitioner askes the family to identify their existing use of this skill

Step 3: The practitioner explains the components of the skill Step 4: The skill is practised through role-play, and other family members and the practitioner give constructive feedback

Step 5: The practitioner asks the family to practise the skill between sessions ('homework') and to make a note of when they do, so that they can report back at the next session

(Falloon 2004; Fadden, 2006a)

become rarer in the context of stress and worry surrounding the mental illness (Hayes 2014).

\section{Goal setting and problem solving}

Goal setting and problem solving follow easily from the communication skills, although a flexible approach is adopted so that they may be taught sooner should a crisis or problem arise in earlier sessions. A typical six-step method is followed, as outlined in Box 5 (Falloon 2004). The practitioner's role is to teach these skills and encourage family members to learn how to use them together.

Use of the term goal setting is a constructive reframing of the term problem solving. Both follow the six steps, but 'goal setting' implies a focus on what is to be achieved and 'problem solving' a focus on what will be modified or eliminated. In

BOX 5 Skills in problem solving and goal setting: steps in training

Step 1: The problem is identified and described as clearly and simply as possible

Step 2: All possible solutions are generated and recorded without censoring or discussion ('brainstorming')

Step 3: Each solution is evaluated by identifying its pros and cons

Step 4: The best solution (or combination of solutions) is selected

Step 5: The family makes specific and detailed plans to implement their chosen solution(s)

Step 6: The family's implementation of the solution(s) is reviewed and any adjustments to the plan are made if the solution could not be fully implemented

(Falloon 2004; Fadden, 2006a) 
practice, many problems can be reframed as goals. For instance, the family problem of 'the house is always a mess and untidy' can be reframed as the goal of 'let's keep the house tidy'. Further, learning goal setting helps all family members to achieve their individual goals (Fadden 2006a; Hayes 2014).

A brief case study illustrating the application of some of these techniques is given in Box 6.

\section{The evidence base for FPE}

\section{Robust evidence}

The most commonly researched effects of FPE concern reduced relapse and admission rates for the person with schizophrenia, for which there is strong evidence. More than 50 randomised controlled trials have been conducted in the past 40 years and synthesised, including in a Cochrane review (Pharoah 2010). Reduced relapse rates of $20 \%$ compared with usual care have been reported, with greater effects for interventions lasting more than 3 months (Pitschel-Walz 2001). Another meta-analysis reported a $48.8 \%$ absolute difference in risk of being re-admitted for single-family interventions (Pilling 2002). Whether multiple family groups are more efficacious than single-family interventions in firstepisode psychosis remains unclear (Rossberg 2010; McFarlane 2012).

The number needed to treat (NNT) is a useful measure of benefit; the NNT is the average number of families (in this case) who need to be treated to prevent one additional negative outcome. The Cochrane review estimated that the NNT to prevent one person with schizophrenia from relapsing is 7 families; further, relapse events were reduced at 12, 18 and 24 months (Pharoah 2010). The lowest NNT has been reported with single-family interventions (Pilling 2002). In addition, FPE may result in improved adherence to medication $(\mathrm{NNT}=6)$ (Pharoah 2010). These effect sizes equate to those delivered by antipsychotic medications routinely used in the treatment of schizophrenia (McFarlane 2012), although the Cochrane review noted that treatment effects may be overestimated owing to the possibility that small negative studies are missing (Pharoah 2010).

\section{Evidence for other benefits}

There is less robust evidence for other outcomes following FPE (McFarlane 2003; Pharoah 2010). For people with schizophrenia, these include improved mental state and important recovery outcomes such as better social functioning and increased employment (e.g. McFarlane 2003; Pharoah 2010).
BOX 6 The application of family psychoeducation (FPE) techniques: case study ${ }^{\mathrm{a}}$
Tom is a 25-year-old single unemployed man living with his mother Sue, father Terry and younger sister Megan. He has a diagnosis of schizophrenia. Tom and his family were offered behavioural family therapy (BFT) after he had two in-patient admissions in the previous year following an exacerbation of auditory hallucinations, alongside increasing withdrawal from the family.

Tom and his family agreed to participate in $\mathrm{BFT}$, although in her individual assessment Sue expressed concern that the sessions would 'stir things up' and add to their difficulties. Individual and family assessments revealed that there was conflict and tension in the household about Tom's lack of involvement in household activities and about some of his behaviours, such as spending a lot of time listening to music alone in his room. The family's understanding of Tom's condition varied, with Terry and Megan having the least knowledge. However, it was also evident that the family wanted to support Tom's recovery and learn more about how to do so.

During the information-sharing sessions, it became apparent that some of the tension was due to misunderstanding and misinterpreting Tom's behaviour. For example, Tom often managed his symptoms by going to his room, as he found listening to music helped him to be less focused on symptoms. The family interpreted Tom's behaviour as 'lazy', since they thought he was avoiding taking part in household tasks. They also worried that he was isolating himself. Terry in particular sometimes shouted at Tom and criticised him. The family's understanding improved greatly when, with the encouragement of the practitioner, Tom was able to describe his experience of his symptoms, his coping strategies and what made his symptoms worse. Terry said: 'Had I not had the sessions, I [would have] still thought yelling would help, when in fact it makes it worse'.

Following this work, Tom and his family developed a 'staying well' plan that included agreed actions if he started showing early signs of relapse, since Tom had identified that he did not want to feel his family might go behind his back to alert the mental health service that he needed an admission. The family's improved mutual understanding and trust further eased the tension in the household.

As trust between the practitioner and the family grew, the family agreed to work on their communication skills. When family members expressed positive feelings towards each other in the session, there was a noticeable lightening of the family atmosphere. Tom's family were able to express their desire that he spend more time with them, so that he could understand how this would help reassure them about his wellbeing. He started to spend a little more time in the living room during the evenings. He commented: 'Well, it sort of just got things off your mind... different things... got out in the open and everyone sort of discussed them more and then it was better'.

When a crisis arose following further conflict between Tom and Terry, the practitioner introduced the whole family to problem solving. This allowed them to resolve the conflict and to see the value of learning this approach to help deal with future problems. Megan particularly benefited from individual goal setting, which helped her to achieve her goals to socialise more and to pursue greater independence.

a. Quotations are taken from $\mathrm{O}^{\prime} \mathrm{Hanlon}$ et al (2016); all names and details have been changed to protect confidentiality.
Family outcomes from FPE are less commonly studied, so the evidence is weaker (Barbato 2000). In the only meta-analysis of 16 studies of family outcomes, FPE had considerable positive effects on relatives' burden and psychological distress, the relationship between relatives and the person with schizophrenia, and family functioning (Cuijpers 1999). Larger effect sizes were found for interventions of more than 12 sessions. However, Cuijpers suggested that the duration of the 
intervention might be more important than the number of sessions. A more recent review of FPE (Lobban 2013) suggested that it was more likely to be found to be effective for families if family knowledge, beliefs and functioning were among the outcomes assessed. There is uncertainty about how FPE works (Lobban 2013). It is generally accepted that FPE approaches have several different domains of effect, ranging from improved problem solving by family members to enhanced social support (McFarlane 2003). Nonetheless, there are calls for research to provide better understanding of the mediators and moderators of effectiveness (Lucksted 2012; Lobban 2013).

\section{Relevance and applicability of FPE}

There is evidence for the efficacy of FPE in schizophrenia from Australia, Canada, China, Europe and the USA (McFarlane 2003). Negative or absent effects among migrant populations (e.g. Latino families in the USA: McFarlane 2003) are best understood as highlighting the need for cultural adaptations, since culturally adapted multiple family groups have been shown to be effective for Vietnamese-speaking Australians and Spanishspeaking Mexican Americans (Bradley 2006; Kopelowicz 2012).

\section{Clinical practice guidelines and routine availability of FPE}

Family psychoeducation is recommended in clinical practice guidelines for psychotic disorders, most notably schizophrenia, in various industrialised countries (Canadian Psychiatric Association 2005; Galletly 2005; Kreyenbuhl 2010; NICE 2014). These guidelines generally propose that families are included in the assessment and treatment process and, in the case of schizophrenia, stipulate that individuals who are at risk of relapse and who are living with, or in frequent contact with, their family should be offered FPE. Some also recommend FPE for persisting symptoms (NICE 2014). Despite these recommendations, and consistent with other psychosocial interventions, FPE is not routinely available in mental health services in these countries. This holds true even after targeted training and follow-up support for practitioners have been provided (Fadden 2006b; Harvey 2013; Killackey 2015).

\section{Practice development and practitioner support}

Common barriers identified in the literature to the use of FPE in mental health settings include those operating at the level of the family (e.g. families' capacity or willingness to commit to a relatively intensive and extended process), the practitioner (e.g. confidence and ability to engage and work with families) and the organisation (e.g. integration of FPE into existing workload) (Dixon 2001; Magliano 2006; Lucksted 2012; Harvey 2013). Linked to these understandings, it is clear that it is necessary to adopt a systemic and multilevel approach to practice change, as recommended in the field of implementation science, to promote widespread availability of FPE (Damschroder 2009; Lucksted 2012; Eassom 2014). It is also evident that ongoing organisational support of changed practice is crucial (Harvey 2013; Hayes 2013; Eassom 2014).

Training practitioners to deliver FPE is, in itself, insufficient to promote widespread availability. Other factors that may contribute to successful implementation of FPE by better supporting trained practitioners include: ongoing supervision; co-working arrangements to build practitioner confidence; and dedicated and protected time for 'FPE champions' (Dixon 2001; Fadden 2006b; Magliano 2006; Harvey 2013; Killackey 2015). The establishment of small specialist FPE teams has also proved successful in building practitioner confidence and skill (Hayes 2013).

\section{Promising future directions for better meeting family needs through family involvement}

For practitioners who have not received FPE training, the concept of a practice element may be useful in advancing their practice in this area. This is based on the understanding that a number of evidence-based interventions have discrete and separable practice elements that are combined in various ways (Chorpita 2005). For example, problem solving and goal setting are common to FPE and social skills training, while FPE and cognitive-behavioural therapy both include a focus on enhancing coping strategies. Thus, a promising approach to practice development is that practitioners already trained in another evidence-based intervention may apply their skills in a particular practice element to their work with families.

Less intensive FPE interventions also require consideration. There is some evidence that eight sessions of brief FPE focusing predominantly on structured didactic information sharing and discussion of coping strategies may be beneficial in reducing re-admissions, although individuals with six or more previous episodes of relapse did not show a positive effect (Pitschel-Walz 2006). A Cochrane review that examined brief family intervention (delivered over five sessions or less, or of no more than 3 months' duration) concluded that meta-analysis was not possible, and the evidence was of low or 
very low quality (Okpokoro 2014). As its authors concluded, further development of brief FPE and research into its value is nonetheless warranted, especially in light of the present state of demand and resources.

There is emerging consensus that FPE needs to be offered to families as one of a number of services, and various stepped or tiered approaches to providing the full range of services have been recommended (Dausch 2012; Farhall 2012; Harvey 2013). This is consistent with the recognition that FPE is not acceptable to all families, even though it has established efficacy. Family psychoeducation may also not be necessary for all families, although our current knowledge of which families might benefit is very much limited to previously described broad applicability criteria contained in clinical practice guidelines and needs further development (Lucksted 2012). These stepped or tiered approaches acknowledge the value of including family peer-to-peer approaches in the suite of available services. These focus on emotional and practical support for relatives and on enhancing their coping strategies. Peer-to-peer approaches have promising, but limited, evidence of benefit and so require further research (Killackey 2015). They also hold potential for reaching more families as the peer workforce develops and expands.

Finally, family consultation may be useful as a way of engaging with families, assessing their needs and helping them to make links with appropriate additional services and interventions. There are various family consultation models, all of which are brief (1-3 sessions) and may be provided by practitioners or family peers (Farhall 2012; Harvey 2013; Killackey 2015). Beyond the value of offering an opportunity for all families to be in contact with mental health services and to find a doorway to other services, family consultation models also increase the overall contact between practitioners and families, which may in turn increase uptake of FPE where required.

\section{Conclusions}

Most people who are living with schizophrenia are supported by their families. The involvement of the family as partners in care has the potential to better support the individual's recovery as well as address the family's needs for information, support and enhanced skills for their caring role. In this regard, there is robust evidence for the benefits of participation in FPE for individuals and their families, which is reflected in recommendations in clinical practice guidelines. Despite this,
FPE is not widely available, and training practitioners in this intervention is a necessary but not sufficient step to address this. It is increasingly clear that systemic and multilevel approaches to practice change, with a strong emphasis on organisational support, are required. Future developments to better support more widespread and effective involvement of families in service delivery include research on how to better engage families, including through less intensive interventions, and enhanced knowledge of how, and to whom, FPE delivers benefits.

\section{References}

Barbato A, D'Avanzo B (2000) Family interventions in schizophrenia related disorder: a critical review of clinical trials. Acta Psychiatrica Scandinavica, 102: 81-97.

Barrowclough C, Tarrier N, Lewis S, et al (1999) Randomised controlled effectiveness trial of a needs-based psychosocial intervention service for carers of people with schizophrenia. British Journal of Psychiatry, 174: 505-11.

Bradley G, Couchman G, Perlesz A, et al (2006) Multiple-family group treatment for English- and Vietnamese-speaking families living with schizophrenia. Psychiatric Services, 57: 521-30.

Brown GW, Birley JLT, Wing JK (1972) Influence of family life on the course of schizophrenic disorders: a replication. British Journal of Psychiatry, 121: 241-58.

Burbach $F$ (1996) Family based interventions in psychosis - an overview of, and comparison between, family therapy and family management approaches. Journal of Mental Health, 5: 111-34.

Canadian Psychiatric Association (2005) Clinical Practice Guidelines: Treatment of Schizophrenia. Canadian Journal of Psychiatry, 50: S1-57.

Carers Trust (2013) The Triangle of Care. Carers Included: A Guide to Best Practice in Mental Health Care in England. Carers Trust.

Chorpita B, Daleiden E, Weisz J (2005) Identifying and selecting the common elements of evidence based interventions: a distillation and matching model. Mental Health Services Research, 7: 5-20.

Cuijpers $P$ (1999) The effects of family interventions on relatives' burden: a meta-analysis. Journal of Mental Health, 8: 275-85.

Damschroder L, Aron D, Keith R, et al (2009) Fostering implementation of health services research findings into practice: a consolidated framework for advancing implementation science. Implemention Science, 7 : $50-65$.

Dausch B, Cohen A, Glynn S, et al (2012) An intervention framework for family involvement in the care of persons with psychiatric illness: further guidance from family forum II. American Journal of Psychiatric Rehabilitation, 15: 5-25.

Dixon L, McFarlane W, Lefley H, et al (2001) Evidence-based practices for services to families of people with psychiatric disabilities. Psychiatric Services, 52: 903-10.

Eassom E, Giacco D, Dirik A, et al (2014) Implementing family involvement in the treatment of patients with psychosis: a systematic review of facilitating and hindering factors. BMJ Open, 4: e006108.

Fadden G (1998) Research update: psychoeducational family interventions. Journal of Family Therapy, 20: 293-309.

Fadden G (2006a) Family interventions. In Enabling Recovery: The Principles and Practice of Rehabilitation Psychiatry leds GRoberts, SDavenport, FHolloway, et al): 158-69. Gaskell.

Fadden G (2006b) Training and disseminating family interventions for schizophrenia: developing family intervention skills with multi-disciplinary groups. Journal of Family Therapy, 28: 23-38.

Falloon I, Fadden G, Mueser K, et al (2004) Family Work Manual. Meriden Family Programme. 
MCO answers
Farhall J, Harvey C, Kazantzis N, et al (2012) Psychological therapies. In Mental Health in Australia (eds GMeadows, JFarhall, EFossey, et al): 468-501. Oxford University Press.

Froggatt D, Fadden G, Johnson D, et al (2007) Families as Partners in Mental Health Care: A Guidebook for Implementing Family Work. World Fellowship for Schizophrenia and Allied Disorders.

Galletly C, Castle D, Dark F, et al (2005) Royal Australian and New Zealand college of psychiatrists clinical practice guidelines for the treatment of schizophrenia and related disorders. Australian and New Zealand Journal of Psychiatry, 39: 1-30.

Gleeson J, Cotton S, Alvarez-Jimenez M, et al (2010) Family outcomes from a randomized control trail of relapse prevention therapy in first-episode psychosis. Journal of Clinical Psychiatry, 71: 475-83.

Harvey C, O'Hanlon B (2013) Family psycho-education for people with schizophrenia and other psychotic disorders and their families. Australian and New Zealand Journal of Psychiatry, 47: 516-20.

Hatfield A (1987) The expressed emotion theory: why families object. Psychiatric Services, 38: 341-41.

Hayes L (2014) Hope and Recovery in a Family Treatment for Schizophrenia: A Program Evaluation of a Family Psychoeducational Intervention (Thesis). University of Melbourne.

Hayes L, Harvey C, Farhall J (2013) Family psychoeducation for the treatment of psychosis. InPsych, 35: 16-17.

Hayes L, Hawthorne G, Farhall J, et al (2015) Quality of life and social isolation among caregivers of adults with schizophrenia: policy and outcomes. Community Mental Health Journal, 51: 591-97.

Killackey E, Harvey C, Amering M, et al (2015) Partnerships for meaningfu community living: Rehabilitation and recovery-informed practices. In Psychiatry (eds A Tasman, J Kay, J Lieverman, et al): 1959-81. John Wiley and Sons.

Kim E, Miklowitz D (2004) Expressed emotion as a predictor of outcome among bipolar patients undergoing family therapy. Journal of Affective Disorders, 82: 343-52.

Kopelowicz A, Zarate R, Wallace C, et al (2012) The ability of multifamily groups to improve treatment adherence in Mexican Americans with schizophrenia. Archives of General Psychiatry, 69: 265-73.

Kreyenbuhl J, Buchanan R, Dickerson F, et al (2010) The Schizophrenia Patient Outcomes Research Team (PORT): updated treatment recommendations 2009. Schizophrenia Bulletin, 36: 94-103.

Kuipers E, Leff J, Lam D (2002) Family Work for Schizophrenia: A Practical Guide. RCPsych Publications.

Lobban F, Postlethwaite A, Glentworth D, et al (2013) A systematic review of randomised controlled trials of interventions reporting outcomes for relatives of people with psychosis. Clinical Psychology Review, 33: 372-82.

Lucksted A, McFarlane W, Downing D, et al (2012) Recent developments in family psychoeducation as an evidence-based practice. Journal of Marital and Family Therapy, 38(1): 101-21.

Magliano L, Fiorillo A, Malangone C, et al (2006) Patient functioning and family burden in a controlled, real-world trial of family psychoeducation for schizophrenia. Psychiatric Services, 57: 1784-91.

McFarlane W, Dixon L, Lukens E, et al (2003) Family psychoeducation and schizophrenia: a review of the literature. Journal of Marital and Family Therapy, 29: 223-45.

McFarlane W, Lynch S, Melton R (2012) Family psychoeducation in clinical high risk and first-episode psychosis. Adolescent Psychiatry, 2, 1-13.
Morgan V, Waterreus A, Jablensky A (2012) People living with psychotic illness in 2010: the second Australian national survey of psychosis. Australian and New Zealand Journal of Psychiatry, 46: 735-52.

Murray-Swank A, Glynn S, Cohen A, et al (2007) Family contact, experience of family relationships, and views about family involvement in treatment among VA consumers with serious mental illness. Journal of Rehabilitation Research and Development, 44: 801-11.

NICE (2014) Psychosis and Schizophrenia in Adults: Prevention and Management (Clinical Guideline CG178). National Institute for Health and Care Excellence.

O'Hanlon B (2015) Building Family Skills Together: Implementing a Family Intervention in an Adult Mental Health Team(Thesis). La Trobe University.

O'Hanlon B, Hayes L, Perlesz A, et al (2016) Understanding the complex family experiences of Behavioural Family Therapy. Journal of Family Therapy, doi: 10.1111/1467-6427.12139.

Okpokoro U, Adams C, Sampson S (2014) Family intervention (brief) for schizophrenia. Cochrane Database of Systematic Reviews, 3: CD009802 (doi: 10.1002/14651858.CD009802.pub2).

Onwumere J, Smith P, Kuipers E (2010) Families and psychosis. In Principles of Social Psychiatry (eds CMorgan, DBhugra): 103-16. Wiley-Blackwell.

Parker R, Leggatt M, Crowe J (2010) Public interest and private concern: the role of family carers for people suffering mental illness in the twenty first century. Australasian Psychiatry, 18: 163-6.

Pharoah F, Mari J, Rathbone J, et al (2010) Family intervention for schizophrenia. Cochrane Database of Systematic Reviews, 12: CD000088 (doi: 10.1002/14651858.CD000088.pub2).

Pilling S, Bebbington P, Kuipers E, et al (2002) Psychological treatments in schizophrenia: I Meta-analysis of family intervention and cognitive behaviour therapy. Psychological Medicine, 32: 763-82.

Pitschel-Walz G, Leucht S, Bauml J (2001) The effect of family interventions on relapse and rehospitalization in schizophrenia - A meta-analysis. Schizophrenia Bulletin, 27: 73-92.

Pitschel-Walz G, Bauml J, Bender W, et al (2006) Psychoeducation and compliance in the treatment of schizophrenia: results of the Munich Psychosis Information Project Study. Journal of Clinical Psychiatry, 67: 443-52.

Rossberg J, Johannessen 0, Klungsoyr 0, et al (2010) Are multi family groups appropriate for patients with first episode psychosis? A 5-year naturalistic follow-up study. Acta Psychiatrica Scandinavica, 122: 384-94.

Tattan T, Tarrier N (2000) The expressed emotion of case managers of the seriously mentally ill: the influence of expressed emotion on clinical outcomes. Psychological Medicine, 30: 195-204.

Vaughn C, Leff J (1976) The influence of family and social factors on the course of psychiatric illness. British Journal of Psychiatry, 129: $125-37$.

Visa B, Harvey C (2015) The Experiences of Mental Health Carers Involved in a Carer Peer Support Program (Thesis), University of Melbourne.

Wallcraft J, Amering M, Freidin J, et al (2011) Partnerships for better mental health worldwide: WPA recommendations on best practices in working with service users and family carers. World Psychiatry, 10: 229-36.

Wynaden D, Orb A (2005) Impact of patient confidentiality on carers of people who have a mental disorder. International Journal of Mental Health Nursing, 14: 166-71.

Zubin J, Spring B (1977) Vulnerability-a new view of schizophrenia. Journal of Abnormal Psychology, 86: 103-26. 
MCOs

Select the single best option for each question stem

1 Families of individuals with schizophrenia:

a are unlikely to have regular contact with those individuals in industrialised societies

b meet criteria for probable anxiety or depression at a rate of about $15 \%$

c have various needs for treatment and support which can only be addressed by providing family psychoeducation (FPE)

d have knowledge that can help practitioners to better support those individuals

e should be offered FPE only if they are assessed as 'high expressed emotion' (high EE).

2 Family psychoeducation (FPE):

a is only recommended for families who live with the individual with schizophrenia

b is acceptable to all families if it is offered by a trained practitioner c may be recommended for individuals with persisting symptoms and their families

$d$ is likely to be more widely available if more practitioners are trained

e addresses the need for a service to offer family peer-to-peer programmes.

3 Common principles of FPE approaches do not include:

a developing an explicit crisis plan that includes professional responses

b encouraging family members to expand their social support networks

c attending to the social and clinical needs of the individual with schizophrenia

d providing advice to the family about how to solve their problems

e being flexible in meeting family needs.
4 Regarding the evidence for FPE:

a culturally adapted multiple family groups are effective

b single-family interventions are more effective in first-episode psychosis

c family relationships, but not family burden, are improved

$d$ brief interventions are as effective as longer interventions

e the number needed to treat (NNT) for improved medication adherence is 7 .

5 The generally agreed critical ingredients of FPE do not include:

a training in goal setting

b cognitive-behavioural techniques

c social skills training

d work with single or multiple families

e duration of at least 9 months. 